\title{
12. Tourism Issues in the Pacific
}

\author{
Susana Taua'a
}

\section{Les problèmes du tourisme dans le Pacifique}

Cet article met en lumière quelques problèmes réels perçus concernant le tourisme dans la région. On constate trois grands domaines qui affectent ce secteur : le domaine social, économique et environnemental. La nature et le caractère de ce secteur dans le Pacifique sont également définis en fonction de ces trois sphères d'influence. La clé pour comprendre le tourisme dans la région est la reconnaissance du fait qu'à la fois le secteur et son contexte, mondial et régional, traversent une période de transition profonde. On a besoin de comprendre les mutations qui se produisent et les raisons de ces mutations afin que le secteur puisse être mieux géré et mieux planifié. Il existe des questions plus larges qui affectent ou qui sont affectées par le tourisme : les migrations internes, l'émigration, la complexité du foncier, le sexe, la gestion de l'information, la restructuration du secteur du transport aérien, le rôle des ONG, la capacité de mettre sur pied les ressources humaines, l'usage des institutions tertiaires régionales comme l'USP (l'Université du Pacifique Sud) et des organismes comme le SPREP et la CPS (Communauté du Pacifique Sud). L'article présente une étude des tendances en matière de tourisme dans la région en mettant l'accent sur les effets économique, social et environnemental, avant de proposer le potentiel du modèle fale de plage samoane comme modèle pour gérer quelques-uns des effets social, économique et environnemental du tourisme dans la région.

\section{Introduction}

This paper attempts to highlight some real and perceived issues concerning tourism in the region. There are three broad areas in which the industry has impacted strongly: social, economic and environmental. The nature and character of the industry in the Pacific is also defined in terms of these three spheres of influence. The key to understanding tourism in the region is a recognition that both the industry and its context, global and regional, are in a state of profound transition. There is a need to understand the changes taking place and the reasons for these changes so that the industry can be better managed and planned. There are broader issues that impact or are impacted upon by tourism: internal migration, emigration, land tenure complexities, gender, information 
Politics, Development and Security in Oceania

management, airline restructuring, the role of NGOs, human resource capacity building, use of regional tertiary institutions such as USP and bodies such as SPREP and SPC.

Tourism in the region is created in those places where the natural environments are unsuitable for farming or forestry - beaches feature strongly - or where there are no valuable minerals. Basically, there are two futures for tourism in the region, the product can be exploited and used up as in a mined out mineral resource, or it can be managed sustainably (Hall and Kearsley 2001; Cleverdon and Milne 2003).

The tourism industry in the Pacific has the capacity to return long-term benefits, but to be able to do this and remain sustainable it needs to satisfy four criteria:

- It must be financial viable and provide real rates of return for investors (local and overseas) and provide worthwhile jobs for its workforce

- It must provide continuing visitor satisfaction. Bad experiences and declining satisfaction levels are rapidly communicated (as in a series of stray dogs attacking tourists in Samoa)

- It should be recognised that while the resources for tourism have often been thought of as the natural environment, many tourists are increasingly drawn to people's cultures (hence the festivals - teuila, hibiscus, heilala) and ways of life which are just as vulnerable

- Tourism must be based upon a supportive host community, very important with the beach fale operation in Samoa.

None of these four criteria operate in isolation, for instance community support is enhanced by the visible flow of dollars and jobs into the local areas although material benefits are often fragmentary and diverse that making such benefits visible is a difficult task. In the same way, without careful resource management, locals may find favourite popular picnic spots and beaches crowded and commodified as tourist 'experiences'. Resource strategies must be developed so that they benefit locals as well as visitors. After all, satisfied visitors are far more likely to interact with locals than are tourists who feel resented or exploited.

\section{Regional Tourism Trends}

There are three types of tourism to the region: business tourism, visiting friends and relatives (this is the most common form in Samoa), and holiday/ leisure tourism. There are also other forms but of a lesser degree of importance such as adventure tourism (surfing/bungy jumping) and special interest tourism (eco-tourism, sports). There has also been a 'new' form of tourism emerging 
since the 1990s that appeals to the experienced and well educated traveller who is looking for much more than just the sun or to gaze at culture. This is a market that's complicated, individual and sophisticated tastes are made possible by advanced information technology and communication - e-commerce and internet booking. It is characterised by variety, diversity, participation and individual flexibility (Poon 1993). It is a customised form of tourism to suit the consumer and the experiences sought are most likely to be much more diverse with a focus on quality environmental experiences, and 'authentic' settings and societies. For example these types of tourists do not seek standard hotels, they patronise backpacking accommodation, bed and breakfast lodgings and beach fale stays. This new form of tourism is an off-shoot of the development of the tourism industry in the Caribbean. It is important for the Pacific in the sense that the product is locally owned and therefore more authentic compared to standardised mass tourism which focuses on large destination resorts, group travels and scheduled tours. This new wave of tourism demands a particular set of products and services, so destinations must provide the facilities and experiences in line with the consumer aspirations. The issue is whether the small island states can do it in a sustainable manner.

The competitive nature of the industry is manifested in the segmentation of destinations in the region into four groups, based on the number of visitor arrivals and source markets (Cleverdon and Milne 2003). Fiji, French Polynesia, New Caledonia and Palau have visitor flows of 100,000+ people a year from Europe, Japan, Australia, New Zealand and North America. The Cook Islands, PNG, Samoa and Tonga have around 30,000-70,000 visitors a year mainly from New Zealand and Australia, and benefit from the long-haul flight services by Air New Zealand and hopefully by Air Pacific in the case of Samoa. The third group (the Federated States of Micronesia and Vanuatu) experiences similar numbers of visitors as the second group and also mainly from the same markets (Australia and New Zealand). American Samoa, Tuvalu, Niue, Nauru, Marshall Islands, Kiribati and Solomon Islands make up the fourth group with modest levels of visitor arrivals due to access constraints, limited airline flights from originating points, leading to high costs of hotel operation and minimising the level of demand.

In addition, the organisation and spatial allocation of capital and tourists in the region is also segmented and unevenly spread, highlighting the core-periphery nature of the industry with Fiji, Tahiti and New Caledonia making up the core while the rest are peripheral destinations. Tourism in the region can be defined and analysed in relationship to issues of economic restructuring, globalisation, and post-Fordist modes of production (Hall 1994; Shaw and Williams 2004) 
where the region is commodified as an 'experience' - a place characterised by a relaxed lifestyle where one is released from the stress of everyday life - to be consumed.

There is competition for the same product, characterised by aggressive marketing campaigns amongst the South Pacific Tourism Organisation (SPTO) member countries. The web advertising of the region is surreal, almost fraudulent: the 'exotic melting pot cultures and fascinating lifestyles of Fiji', the 'pristine aqua-marine waters of Samoa', the 'sugary-white magical beaches' of Tahiti, the 'spectacular marine life and timeless Tuvalu' and 'the strict observance of the Sabbath and the strong influence of the church provide a fascinating experiences for tourists' in Tonga (SPTO Country Report). These claims conceal the environmental, economic, social and governance problems confronting the region. They are marketed as 'premium' destinations based on quality, safety, and their unique and diverse cultures. Product differentiation must take into account the great diversities in the culture, size, resources, private sector, and the different needs of SPTO countries.

We know for a fact that the economies of the island states are driven by tourism, and virtually all governments in the region have identified the industry as a priority sector for future economic growth through foreign direct investment, so I am not going to dwell on this except to cite some examples to illustrate the point. The SPTO suggests target revenue for the region from tourism of US $\$ 2$ billion per annum by 2010. If this is achieved tourism would be the largest contributor to 'Pillar 1' of the Pacific Plan (OSTA 2008:20). In Fiji, tourism was 25.6 per cent of GDP in 2009 and is expected to increase to 27.8 per cent in 2019, providing 91,000 jobs - or 23.5 per cent of total employment (World Travel and Tourism Council). In Samoa, tourism has boomed since 2005 and in 2007 visitor flow exceeded the 100,000 mark (but that was due to the South Pacific games - a one-off special interest tourism event). Tourism contributed 25 per cent of GDP in Samoa in 2006 (Human Development Report 2006). In Palau, tourism accounts for 67 per cent of GDP, and in the Cook Islands, 50 per cent of GDP. In 2007, strong visitor growth was recorded in Papua New Guinea (+34 per cent), Solomon islands (+19.7 per cent), Vanuatu $(+19.3$ per cent), Tonga $(+16.7$ per cent) and Kiribati (6.9 per cent) (South Pacific Tourism Organisation: 19). Growth was driven by increased cheap air services (for example, Polyblue, a no-frills service) and destination marketing. In Samoa, the category of Visiting Friends and Relatives (VFR) made up 51 per cent of total visits in 2006 (Ministry of Finance 2007). In terms of volume, Samoa has the highest proportion of VFR visitors (35-40 per cent) in the region, followed by Tonga (33 per cent), Fiji (19 per cent) and Cook Islands (4 per cent) (Kavesi 2000). In Tonga, tourism contributes 12.2 per cent of GDP and 10.5 per cent of total employment in 2009 (World Travel and Tourism). 
Developing a regional cruise shipping strategy to strengthen regional cooperation and integration (Pacific Island Forum Auckland Declaration 2004) based on the cruise tourism experiences of Fiji, Kiribati (as a remote new destination), PNG and Vanuatu would only serve to highlight the differences in size, population and resource endowments. In order to develop cruise ship tourism we need to promote the region's cultural richness and natural beauty. The issues identified in the cruise ship strategy for action are based on the four beacons approach which are: 1) shore excursions and land based activities; 2) marine infrastructure and support services; 3) institutional management and cooperative frameworks; and 4) cruise destination marketing and promotion (South Pacific Cruise Shipping Development Strategy 2007:3). Samoa attempted to boost cruise ship visits and went all the way to Europe to promote Samoa as a possible destination and reported an increase from eight to twenty visits per year. In comparison, Port Vila gets 60 visits per year. Old ports have been rebuilt, turned into international ports in the past 12 months and have yet to receive cruise ship visits. Overall, the region is rated highest for friendliness of the locals (1.57, where one is excellent and five is poor), and lowest for safety/medical facilities (3.6) and port cleanliness (3.57) (Regional Cruise Shipping Strategy 2007:22).

As mentioned earlier, tourism is in a state of transition throughout the world, with the Pacific no exception. The industry is emerging as one of the few industries that can supply jobs, profits and growth. So it is essential that tourism should thrive and grow in ways that do not jeopardise its own future wellbeing, nor impose unacceptable pressures on the environment or society - that is, it must be sustainable, not only in itself, but also in terms of its wider context. As development practitioners, we can devise models of the broad parameters of sustainable tourism for the individual states in the region, but I am uncertain whether all stakeholders - the industry, host communities, visitors and resource managers - see sustainability in the same light. Commitment to sustainable tourism in the Pacific Islands is not always translated into practice (Harrison 2004:13). Table 1 shows the results of a 2007 survey of 30 members of the tourism industry in Samoa, randomly selected from a number of sources such as the operators of beach fales, hotel and tour operators and administrators, which reveals some attitudes towards sustainability and associated issues in Samoa.

Table 5: Knowledge/ldea of Sustainable Tourism

\begin{tabular}{|l|r|r|}
\hline \multicolumn{1}{|c|}{$\begin{array}{c}\text { Extent of } \\
\text { knowledge }\end{array}$} & \multicolumn{1}{c|}{$\begin{array}{c}\text { No. of } \\
\text { responses }\end{array}$} & \multicolumn{1}{c|}{ Percentage } \\
\hline A great deal & 2 & $7 \%$ \\
\hline Quite a bit & 3 & $10 \%$ \\
\hline Moderate & 6 & $20 \%$ \\
\hline Very little & 7 & $23 \%$ \\
\hline None & 9 & $30 \%$ \\
\hline No response & 3 & $10 \%$ \\
\hline
\end{tabular}


One in three respondents did not give an answer, so it is not surprising that many people felt they needed to know more about sustainable tourism. Over 50 per cent said that they felt they needed to know more. Some of the respondents' comments about issues pertaining to sustainable practices within the tourism industry reflected the lack of understanding and awareness about sustainable tourism, for instance:

We needed to clear the big trees near the fales because there is too much rubbish from the leaves, and adds to breeding grounds for mosquitoes which is bad for business (26 year old female, April 2009).

I grew up here in Lalomanu, and our family have lived here for hundred years, and yes there are some changes to the beach face but it has always been like that in the past, the sea, beach, land is part of our culture and will remain when we are gone (60 year old male, April 2009).

\section{Social Impacts}

Governments of the region are focussing on the macro-economic impacts and potential for growth of tourism to trickle down to the poor and marginalised communities. This is all very well, but it needs to be incorporated into the tourism agenda as an additional policy objective (Kennedy and Dornan 2009).

Tourism is more often than not made the scapegoat for the social ills in the region. Prostitution, cultural change and environmental deterioration are not necessarily a result of tourism. The mass media and other socio-economic developments are also responsible if not sole contributors.

Crowding (which is the negative perception of the numbers of groups or individuals in a particular setting) is not a measure of density although it reflects it, but it is an indicator that social carrying capacities have been breached (Hall and Kearsley 2001). A commonly used measure of crowding in the region's tourism sites is the concept of encounter norms - that is, the number of groups, families or individuals that a person meets in a given setting. The beach fale context in Samoa is a good example to illustrate this perceptual construct, particularly over the festive season and public holidays such as Children's Sunday where parents normally would treat the children for a swim and picnic at the beach. 


\section{Environmental Trends}

Michael Hall and Stephen Page have written extensively on the environmental and ecological impacts of tourism on the Pacific islands including the clearing and dredging of mangroves and estuaries for resorts and golf courses and the near shore vegetation clearance for beach fale space which has accelerated coastal erosion and coastal pollution. On the other hand, tourism can contribute significantly to environmental protection and conservation through sound environmental management of tourism facilities, especially the large hotels and resorts. If it is to be sustainable in the long run, then it must incorporate the principles and practices of sustainable consumption, important for the fragile ecosystems of small islands like Samoa. Should locals/Pacific islanders reduce their ecological footprints to allow for massive uncontrolled consumption of global and regional resources in the name of tourism?

\section{The Samoan Experience: The Beach Fale}

This industry can be described as young or new. It only managed to adopt a modern approach to marketing and promotion after the two destructive cyclones in 1990 and 1991 and the taro leaf blight in 1993 that destroyed the islands' agriculture and main export earner (Twining-Ward and Twining-Ward 1998). Prior to that, the Samoan government were not too keen to develop and promote mass tourism. The 1992 -2001 Tourism Development Plan emphasised a policy of 'low volume, high yield' and an industry that was environmentally responsible and culturally sensitive. The development of tourism in the early 1990s can be described as cautious and small-scale oriented with a focus on sustainable tourism and attracting higher spending leisure tourists who require upmarket accommodation options.

Despite plans to attract higher spending tourists, the most obvious growth area in the last 15 years has been within the 'beach fale' sector which is categorised as a small-medium enterprise. A beach fale is an oval shaped hut with wooden posts supporting a thatch/corrugated iron roof, with a wooden floor, either with no walls but woven coconut leaf blinds or a tarpaulin for privacy and to protect against the elements (Scheyvens 2005). The beach fale approach to tourism for small island states such as Samoa is an example of 'best practice' tourism for various reasons:

- It is advocated as a 'pro-poor' form of development where the grass roots benefit directly from the backward and forward linkages entailed in the operation 
- It provides for a 'sustainable livelihood' of rural Samoan families - rural based industry and people-centred (Haughey 2007:16). The 'sustainable livelihood' approach to development specifies that a household's livelihood depends on assets (social, human, financial, natural) at their disposal which can be harnessed to achieve a desirable/acceptable level of socialeconomic wellbeing for the household(s). These assets are fundamental to the establishment of beach fales in the first instance and there is adequate continuous supply of these 'factors of production' for further expansion of beach fale tourism.

- It integrates subsistence and cash-based livelihoods in that subsistence production is enhanced or encouraged by the availability of a 'market' for fish, pork, crayfish, vegetables, fruit and root crops (Rosalote, Litia, Tanu and Vacations beach fale consultations 2009).

- There are direct links with the invisible but growing 'informal economy' both in urban and rural Samoa. Previous work on the informal sector suggests strong linkages between beach fale operations and village hawking in handicrafts such as printed wraparound lava-lavas, tee shirts, woven fans and table mats, coconut and shell trinkets, and souvenirs.

- Women feature strongly in beach fale operations as owners and managers because of their organisational, hospitality and financial skills (Haughey 2007). Having women run beach fale operations empowers them socially, economically with some financial independence.

- It is an authentic way to experience the culture of the place, in this case the 'faa Samoa' and simple living. However it should be noted that beach fale operations are evolving away from simple open fales to enclosed modernised self-contained units in response to demands for privacy and comfort, which appeals to families with young children, older travellers and couples. However, 'authenticity' is a matter of degree, and the average tourist can only bear two to three days of sleeping in an open fale exposed to the elements, especially the rain, in a sandy bed, feeling oily and sticky (Haughey 2007: 53-55).

- These fale are privately (family) funded either locally or from remittances. Two beach fale owners (one on Upolu and the other in Savaii) who were interviewed stated that their cattle farm and small retail shop supported the early beginnings of their beach fale venture which started with two small fales. They have reclaimed the land and added four other fales and a smallmedium sized conference room. All these extension to the business have been funded by the cattle farm, shop, bakery (which supplies other small shops with biscuits (popo and masi saina) and buns, and from children living overseas. Access to commercial bank borrowing has been difficult due to land tenure issues where 80 per cent of the land is customary owned and 98 per cent of beach fale operations in Samoa are located on customary owned land. 
- Beach fale operations have a minimum impact on the environment but are very vulnerable to natural disasters. The latest earthquake on 29 September 2009 highlighted the vulnerability of beach fales to the forces of nature.

\section{Future Trends}

Beach fale tourism will continue to feature strongly in Samoa. While the latest disaster destroyed 50 per cent of beach fale operations in the country, this will only serve to improve planning and setting standards - building code, resettlement patterns, sewage disposal - to minimise loss should there be a repeat of the 29 September disaster. We need to think locally while maintaining good quality international standards in accommodation.

Given that Samoa lacks the facilities for large scale tourism, nature-based tourism (or eco-tours) can be applied to smaller states, and I am hoping that we leave the promotion and development of mass tourism such as cruise shipping to the larger states of New Caledonia, PNG, Fiji, and concentrate on beach fales and small- to medium-sized operations.

Tourism in the region is generating a range of social, economic and environmental impacts, although they vary greatly across islands, the impacts invariably manifest upon the islands communities at all stages of their respective developments. For this reason, there needs to be a longitudinal study of community attitudes to beach fale tourism, to monitor the cumulative impacts of beach fale tourism in the context of broader demographic, economic and social forces that moderate tourism on small islands and will provide some explanation for the change in community attitudes to tourism over time.

Tourism in the islands will be affected by global travel and tourism which is expected to grow more rapidly in the coming years, probably outpacing the growth of world economic output. The industry in Asia Pacific is projected to grow at 8 per cent and the South Pacific will share in this growth. But the growth of the industry will require the removal of some major internal constraints such as inadequate, low quality infrastructure, land tenure restrictions. Also, there is a demand for small island states to focus on specialty tourism to meet growing global interests for clean, green, unspoilt natural environments especially for health-conscious travellers. Lastly, the islands need to work in partnership with academic institutions, regional organisations, the private sector and the donor community to develop sustainable tourism practices. The Oceania Sustainable Tourism Alliance in collaboration with Victoria University are working with Pacific islands to 'produce a new road map for the growth of their tourism industry, a road map that sees island tourism as carbon clean' (OSTA 2008:20). 
Politics, Development and Security in Oceania

\section{References}

Cleverdon, R., and Milne, S. 2003. Negotiating Framework For Economic Partnership Agreement Negotiations With The European Union Tourism Study. UK/EU Brussels: Robert Cleverdon Associates.

Haughey, A. 2007. 'Beach Fale Tourism for Pro-poor Development: A Study of Expectations in Rural Samoa'. Unpublished dissertation. Lincoln University, Christchurch.

Hall, C.M., and Kearsley, G. 2001. Tourism in New Zealand: An Introduction. Oxford: Oxford University Press.

Hall, C.M. 1994. Tourism and Politics: Policy, Power and Place. Chichester: John Wiley.

Hall, C.M., and Page, S. 2006. The Geography of Tourism and Recreation: Environment, Place and Space. Abingdon and New York: Routledge.

Harrison, D. 2004. 'Tourism in Pacific Islands'. Journal of Pacific Studies. 26(1 \&2): 1-28.

Kennedy, K., and Dornan, D. 2009. 'An overview: tourism non-governmental organisations and poverty reduction in developing countries'. Asia Pacific Journal of Tourism Research. 14(2): 183-200.

Oceania Sustainable Tourism Alliance(OSTA). 2008. 'South Pacific Island Tourism: A Carbon Clean Future'. Available at: http://www.oceaniatourismalliance. net/Documents/OSTA \% 20Pacific \% 20Island \% 20Carbon \% 20Clean \% 20 Tourism \% 200ct \% 202008.pdf

Poon, A. 1993. Tourism, Technology and Competitive Strategies. Wallingford: CABI Publishing.

Scheyvens, R. 2005. 'Growth of beach fale tourism in Samoa: the high value of low cost tourism', in C.M. Hall and S. Boyd (eds), Nature-Based Tourism in Peripheral Areas: Development or Disaster? Clevedon: Channel View: 173187.

Shaw, G., and Williams, A.M. 2004. Tourism and Tourism Spaces. Sage, London.

Singh, T.V. 2003. 'Tourism and development: not an easy alliance', in R.N. Ghosh, M.A.B. Siddique and R. Gabbay (eds), Tourism and Economic Development: Case Studies from the Indian Ocean Region. Aldershot: Ashgate: 30-41. 
South Pacific Tourism Organisation. 2007. South Pacific Cruise Shipping Development Strategy. Available at http://www.south-pacific.travel/spto/ export/sites/spto/tourism_resources/cruise_shipping/south_pacific_cruise_ dev_strategy.pdf

Twining-Ward, L. and Twining-Ward, T. 1998. 'Tourism Development in Samoa: Context and Constraints'. Pacific Tourism Review. 2: 261-71. 